\title{
Influence of ABCB1 gene polymorphism on concentration to dose ratio and adverse effects of tacrolimus in Pakistani liver transplant recipients
}

\author{
Fahad Azam ${ }^{1}$, Moosa Khan', \\ Tanwir Khaliq ${ }^{3}$, Abu Bakar Hafeez Bhatti ${ }^{4}$
}

\begin{abstract}
Objective: To evaluate the possible association of $A B C B 1$ single nucleotide polymorphism (SNPs) of the $A B C B 1$ gene with tacrolimus dosages, concentration-to-dose ratios (CDR) and adverse effects in Pakistani liver transplant recipients.

Methods: This observational study was conducted at Shifa International Hospital, Shifa Tameer-e-Millat University, Islamabad and Basic Medical Sciences Institute, Karachi from September 2016 to July 2020. Eighty-one liver transplant recipients were included. Demographics, clinical data, tacrolimus trough levels and doses were monitored. Electrochemiluminescence immunoassay (ECLIA) was used to measure tacrolimus trough levels. Transplant recipients were genotyped for three ABCB1 SNPs (rs1045642, rs2032582 and rs1128503). Acute cellular rejection (ACR), sepsis and other adverse events were monitored.

Results: ABCB1 rs1045642 CC genotype showed lower tacrolimus CDR as compared to CT and TT genotype in the first week of the post-transplantation period $(p=0.02)$. There was a significant association of polymorphisms in rs1045642, rs2032582 and rs 1128503 with psychosis, sepsis and ACR respectively.

Conclusion: Identification of ABCB1 rs1045642 polymorphism may shorten the time to achieve optimum levels of tacrolimus during dose titration. ABCB1 polymorphism rs1045642, rs2032582 and rs1128503 may predict adverse effects in liver transplant recipients receiving tacrolimus.
\end{abstract}

KEYWORDS: Adverse effects, Immunosuppression, Liver transplant, Tacrolimus.

doi: https://doi.org/10.12669/pjms.37.3.3898

How to cite this:

Azam $F$, Khan M, Khaliq $T$, Bhatti ABH. Influence of $A B C B 1$ gene polymorphism on concentration to dose ratio and adverse effects of tacrolimus in Pakistani liver transplant recipients. Pak J Med Sci. 2021;37(3):689-694.

doi: https://doi.org/10.12669/pjms.37.3.3898

This is an Open Access article distributed under the terms of the Creative Commons Attribution License (http://creativecommons.org/licenses/by/3.0), which permits unrestricted use, distribution, and reproduction in any medium, provided the original work is properly cited.

1. Dr. Fahad Azam, M.Phil,

Associate Professor, Pharmacology \& Therapeutics,

Shifa Tameer-e-Millat University, Islamabad.

2. Dr. Moosa Khan, PhD,

Professor, Pharmacology and Therapeutics,

Shaheed Zulfiqar Ali Bhutto Medical University, Islamabad.

3. Dr. Tanwir Khaliq, FCPS,

Professor, Department of Surgery,

Shaheed Zulfiqar Ali Bhutto Medical University, Islamabad.

4. Dr. Abu Bakar Hafeez Bhatti, FCPS, FRCS

Consultant, Liver Transplant,

Shifa International Hospital, Islamabad

Correspondence:

Dr. Fahad Azam, MPhil,

Associate Professor, Pharmacology \& Therapeutics, Shifa Tameer-e-Millat University H-8/4,

Islamabad, Pakistan.

Email: fahad.scm@stmu.edu.pk

* Received for Publication:

November 9, 2020

* Revision Received:

* Revision Accepted:

\section{INTRODUCTION}

Liver transplant (LT) is a curative procedure for end-stage liver disease and is followed by immune suppression therapy in transplant recipients. ${ }^{1}$ The use of tacrolimus for post-liver transplant immune suppression was first reported in the year 1989; since then, tacrolimus has become a popular post solid organ transplantation immunosuppressant agent and is also used in the treatment of autoimmune disorders by using oral, sublingual or intravenous route. It acts by blocking calciumdependent phosphatase enzyme calcineurin, thereby suppressing signal 2 which is required for T cell activation. ${ }^{2}$

Tacrolimus is preferred in LT recipients owing to high potency; however, its use is subject to nar- 
row therapeutic index, inter-individual variability resulting in altered concentration-to-dose-ratio (CDR) and serious adverse effects such as neuroand nephrotoxicity necessitating therapeutic drug monitoring of tacrolimus in LT recipients. ${ }^{3}$ Despite close monitoring and keeping blood levels within the optimal range, tacrolimus is associated with adverse effects or may result in a lack of efficacy suggesting a possible influence of genetic polymorphism on inter-individual variability in clinical response. ${ }^{4}$ Genetic polymorphism in cytochrome P4503A4, cytochrome P4503A5 and ABCB1 genes has been found to be associated with variable clinical response of tacrolimus in transplant recipients. ${ }^{5,6}$

An important product of the ATP-binding cassette transporter (ABCB1) gene is P-glycoprotein (P-gp) which is an efflux transporter and regulates oral absorption of many drugs and endogenous substances; $\mathrm{ABCB} 1$ polymorphism could therefore result in altered P-gp expression and variable clinical response to tacrolimus. ${ }^{6}$ The synonymous rs1045642A single-nucleotide polymorphism (SNP) of the ABCB1 gene in exon 26, 3435C $>$ T may affect folding of the P- glycoprotein thereby changing the specificity of the substrate and has therefore been implicated for inter-individual variability in clinical response of tacrolimus. ${ }^{7}$ Transplant recipients homozygous for this variation would consequently have decreased expression of intestinal P-gp and this SNP has been reported widely in 40-45\% Caucasians and less frequently in other ethnicities. Association of this polymorphism by linkage disequilibrium with other SNPs rs1128503 1236C>T and rs2032582 G2677T/A, has also been reported which could eventually result in altered plasma levels of tacrolimus. ${ }^{8}$

Administration of personalized doses of tacrolimus may reduce the time to achieve optimal levels of tacrolimus with minimum adverse effects in the clinical setting. Currently, we do not have any data regarding relevant polymorphisms especially the ABCB1 gene and its effects on trough levels of tacrolimus in the early post-transplantation period in the Pakistani population. With this background, the present study was conducted to evaluate the influence of $A B C B 1$ gene polymorphisms on tacrolimus dosage and adverse effects in Pakistani liver transplant recipients.

\section{METHODS}

The study was conducted at Shifa Tameer-e-Millat University, Shifa International Hospital Islamabad and Basic Medical Sciences Institute Karachi from September 2016 to July 2020 after taking approval from the Institutional Review Board of Shifa Tameer-e-Millat University (IRB\#638-0862016 dated 29-06-2016). This was an observational prospective study and eighty-one patients were enrolled after obtaining written informed consent. All liver transplantations were performed after seeking approval from the Human Organ Transplant Authority (HOTA) Pakistan and were conducted in accordance with the Helsinki Declaration. Eighty-one patients (sixty male and twentyone female) patients were enrolled. The mean age of the patients was $47.82 \pm 10.02$ Baseline characteristics, demographic data and laboratory investigations were recorded for all transplant recipients. Details of the evaluation process of the donors and recipients have been reported elsewhere.,10

Immunosuppression was initiated 8-12 hours post-transplantation through oral or nasogastric route. Tacrolimus and steroids were the standard drugs to initiate immunosuppression; tacrolimus was initiated with $0.5 \mathrm{mg} /$ day on the first-day post-transplantation. Venous blood samples of patients were collected in $5 \mathrm{~mL}$ EDTA plastic tubes. Electrochemiluminescence immunoassay (ECLIA) was used to measure tacrolimus trough levels and adjustments were made in the dosing of tacrolimus based on relevant clinical indices, adverse effects and CDR. ${ }^{11}$ Bilirubin, AST, ALT, creatinine and albumin were evaluated on daily basis. Criteria for diagnosing nephrotoxicity were serum creatinine levels $\geq 1.45 \mathrm{mg} / \mathrm{dl}$; neurotoxicity manifested as seizures, tremors or psychosis; sepsis as signs of consistent fever, increased WBC count and the risk of organ dysfunction. Acute cellular rejection (ACR) was a diagnosis of exclusion and was diagnosed on abrupt derangement of liver enzymes when all probable causes of transaminitis were ruled out.

Genomic DNA was isolated using the standard proteinase $\mathrm{K}$ and phenol extraction method. The sequences of primers of candidate genes were downloaded from the NCBI dbSNP database (https:// www.ncbi.nlm.nih.gov/snp) and were designed as follows: ABCB1 rs1045642, (forward 5'-GATCTGTGAACTCTTGTTTTCA-3' and reverse 5'-GAAGAGAGACTTACATTAGGC-3'); ABCB1 rs2032582 (forward 5'-TCAGCATTCTGAAGTCATGGAA-3' and reverse 5'-TTAGAGCATAGTAAGCAGTAGGGAGT-3'); ABCB1 rs1128503 (forward 5'TCTTTGTCACTTTATCCAGC-3' and reverse 5'TCTCACCATCCCCTCTGT-3').

PCR mixture consisted of $12 \mu 112.5 \mathrm{mM}$ PCR Master Mix (5x FIREpol $^{\circledR}$ Solis BioDyne), $2 \mu 1$ 
genomic DNA, $1 \mu$ forward and reverse primer each and $9 \mu \mathrm{l}$ PCR water in a final volume of $25 \mu 1$. PCR was performed in a GeneAmp PCR system, Thermal Cycler BioRAD T100(USA) for all SNPs under these conditions: initial denaturation at $95^{\circ} \mathrm{C}$ for five minutes followed by thirty-five cycles of denaturation at $95^{\circ} \mathrm{C}$ for 30 seconds, annealing of primers at $60^{\circ} \mathrm{C}$ for thirty seconds and primer extension at $72^{\circ} \mathrm{C}$ for 30 seconds and final step at $72^{\circ} \mathrm{C}$ for ten minutes. Reaction products were analyzed by gel electrophoresis on $2 \%$ agarose gel. The PCR products of SNPs rs1045642, rs2032582 and rs1128503 in ABCB1 were then submitted to MboI, Bseyl and Eco01091 restriction enzymes.

ABCB1 rs1045642 amplified fragment length was $244 \mathrm{bp}$ and cleaved by $\mathrm{MboI}$ into fragments of 175 and $69 \mathrm{bp}$ with subsequent PCR products of CC, CT and TT genotypes. ABCB1 rs2032582 with 485bp was cleaved by Bseyl into fragments of 384 and 101 with PCR products of GG, GT and TT and ABCB1 rs1128503 with fragment length of 502bp was cleaved by Eco01091 into 382 and 120 fragments with CC, CT and TT PCR products.

Quantitative variables were expressed as Mean \pm Standard deviation (SD). Categorical variables were presented as values with percentages and compared by using Pearson's $X^{2}$ tests. Genotype data analysis were performed by using SPSS version 23.0 (SPSS Inc., Chicago, IL, USA). A twotailed $p$-value $<0.05$ was considered significant.
Table-I: Demographic and clinical characteristics.

\begin{tabular}{lc}
\hline Variables & $\begin{array}{c}\text { Recipients }(N=81) \\
(\text { Mean } \pm S D)\end{array}$ \\
\hline Age $($ years $)$ & $47.82 \pm 10.02$ \\
BMI $\left(\mathrm{kg} / \mathrm{m}^{2}\right)$ & $26.35 \pm 4.67$ \\
MELD score & $21.77 \pm 5.39$ \\
Tacrolimus (CDR) $(\mathrm{ng} / \mathrm{ml} / \mathrm{mg} /$ day $)$ & \\
Week-1 & $2.39 \pm 2.02$ \\
Week-2 & $3.33 \pm 2.27$ \\
Week-3 & $1.99 \pm 1.19$ \\
Week-4 & $2.01 \pm 0.90$ \\
Etiology & $n(\%)$ \\
HCV & $40(49.38)$ \\
HBV, ESLD & $12(14.81)$ \\
HBV, HDV & $12(14.81)$ \\
HDV & $8(9.87)$ \\
Cryptogenic liver cirrhosis, HCC & $2(2.46)$ \\
Other & $7(8.64)$ \\
Demographic data & $n(\%)$ \\
Male/female & \\
Ethnicity & \\
Punjabi & \\
Pathan & \\
Sindhi & $13(13.07) / 21(25.92)$ \\
Urdu speaking & \\
Others & $3(11.1)$ \\
\hline
\end{tabular}

\section{RESULTS}

Mean body mass index of study participants was $26.35 \pm 4.67 \mathrm{~kg} / \mathrm{m}^{2}$. Sixty out of the eighty-

Table-II: Tacrolimus CDR according to recipients' genotype.

\begin{tabular}{|c|c|c|c|c|c|}
\hline \multirow[t]{2}{*}{ rs numbers } & \multirow[t]{2}{*}{ Weeks } & \multicolumn{3}{|c|}{$\begin{array}{l}\text { CDR of Recipients (Mean } \pm S D)(n g / m l / m g / d a y) \\
\qquad(N=81)\end{array}$} & \multirow[t]{2}{*}{$p$-value } \\
\hline & & $C C(n=18)$ & $C T(n=30)$ & $T T(n=33)$ & \\
\hline \multirow[t]{6}{*}{ rs1045642 } & Week-1 & $1.36 \pm 0.91$ & $3.02 \pm 2.03$ & $2.39 \pm 2.26$ & $0.02^{*}$ \\
\hline & Week-2 & $3.14 \pm 1.69$ & $4.02 \pm 2.77$ & $2.83 \pm 1.94$ & 0.10 \\
\hline & Week-3 & $1.89 \pm 1.29$ & $2.16 \pm 1.24$ & $1.90 \pm 1.12$ & 0.64 \\
\hline & Week-4 & $1.98 \pm 0.79$ & $2.10 \pm 0.95$ & $1.95 \pm 0.94$ & 0.80 \\
\hline & Mean & $2.09 \pm 0.88$ & $2.82 \pm 1.17$ & $2.27 \pm 1.08$ & $0.04^{*}$ \\
\hline & & $G G(n=9)$ & $G T(n=33)$ & $T T(n=39)$ & \\
\hline \multirow[t]{6}{*}{ rs2032582 } & Week-1 & $2.77 \pm 2.54$ & $2.20 \pm 1.54$ & $2.47 \pm 2.28$ & 0.72 \\
\hline & Week-2 & $2.40 \pm 1.64$ & $3.33 \pm 2.15$ & $3.56 \pm 2.49$ & 0.39 \\
\hline & Week-3 & $1.15 \pm 0.56$ & $2.05 \pm 1.0$ & $2.14 \pm 1.38$ & 0.08 \\
\hline & Week-4 & $1.70 \pm 0.75$ & $2.0 \pm 0.91$ & $2.10 \pm 0.94$ & 0.50 \\
\hline & Mean & $2.00 \pm 0.87$ & $2.40 \pm 0.997$ & $2.56 \pm 1.23$ & 0.39 \\
\hline & & $C C(n=4)$ & $C T(n=37)$ & $T T(n=40)$ & \\
\hline \multirow[t]{5}{*}{ rs1128503 } & Week-1 & $2.05 \pm 2.44$ & $2.39 \pm 2.33$ & $2.43 \pm 1.71$ & 0.94 \\
\hline & Week-2 & $2.44 \pm 0.99$ & $3.17 \pm 1.97$ & $3.58 \pm 2.61$ & 0.54 \\
\hline & Week-3 & $1.10 \pm 0.41$ & $2.04 \pm 1.26$ & $2.04 \pm 1.15$ & 0.32 \\
\hline & Week-4 & $1.64 \pm 0.66$ & $2.03 \pm 0.91$ & $2.03 \pm 0.93$ & 0.70 \\
\hline & Mean & $1.81 \pm 0.74$ & $2.41 \pm 0.94$ & $2.52 \pm 1.27$ & 0.47 \\
\hline
\end{tabular}

*(statistically significant). 
one recipients were male and the most common aetiology was HCV. The patients' demographic and clinical characteristics are presented in Table-I. CC genotype individuals at rs1045642 had significantly less CDR in comparison to other genotypes during week $1 \quad(p=0.02)$. A comparison of CDR of participants based on pharmacogenetic testing of ABCB1 rs1045642, rs2032582 and rs1128503 genotype are shown in Table-II.

Polymorphism in rs2032582 showed a significant association with sepsis $(p=0.002)$, rs1045642 with psychosis $((p=0.002)$ and rs1128503 polymorphism with higher incidence of ACR $(p=0.04)$. Details of adverse effects and ACR with reference to ABCB1 genotype polymorphism are provided in Table-III.

\section{DISCUSSION}

Genetic polymorphism associated with genes regulating absorption and metabolism of calcineurin inhibitors has an important contribution towards unpredictable response which eventually

Table-III: Tacrolimus adverse effects according to recipients' genotypes.

\begin{tabular}{|c|c|c|c|c|c|}
\hline \multirow[t]{2}{*}{ Genotype } & \multirow[t]{2}{*}{ Adverse Effects (n) } & \multicolumn{3}{|c|}{ Genotype $n(\%)(N=81)$} & \multirow[t]{2}{*}{$p$-value } \\
\hline & & $C C(n=18)$ & $C T(n=30)$ & $T T(n=33)$ & \\
\hline \multirow[t]{13}{*}{ rs1045642 } & Adverse effects $(+)(28)$ & $3(3.70)$ & $13(16.04)$ & $12(14.81)$ & 0.14 \\
\hline & Adverse effects (-) (53) & $15(18.51)$ & $17(20.98)$ & $21(25.92)$ & \\
\hline & Psychosis (+) (18) & $1(1.23)$ & $13(16.04)$ & $4(4.93)$ & $0.002^{*}$ \\
\hline & Psychosis (-) (63) & $17(20.98)$ & $17(20.98)$ & $29(35.80)$ & \\
\hline & Seizures $(+)(11)$ & $2(2.46)$ & $6(7.40)$ & $3(3.70)$ & 0.46 \\
\hline & Seizures (-) (70) & 16(19.75) & $24(29.62)$ & $30(37.0)$ & \\
\hline & Nephrotoxicity (+) (12) & $2(2.46)$ & $4(4.93)$ & $6(7.40)$ & 0.79 \\
\hline & Nephrotoxicity (-) (69) & $16(19.75)$ & $26(32.09)$ & $27(33.33)$ & \\
\hline & ACR (+) (13) & $4(4.93)$ & $6(7.40)$ & $3(3.70)$ & 0.37 \\
\hline & $\operatorname{ACR}(-)(68)$ & $14(17.28)$ & $24(29.62)$ & $30(37.0)$ & \\
\hline & Sepsis $(+)(20)$ & $2(2.46)$ & $9(11.11)$ & $9(11.11)$ & 0.34 \\
\hline & Sepsis (-) (61) & $16(19.75)$ & $21(25.92)$ & $24(29.62)$ & \\
\hline & & $G G(n=9)$ & $G T(n=33)$ & $T T(n=39)$ & \\
\hline \multirow[t]{13}{*}{ rs2032582 } & Adverse effects (+) (28) & $1(1.23)$ & 11(13.58) & $16(19.75)$ & 0.26 \\
\hline & Adverse effects (-) (53) & $8(9.87)$ & $22(27.16)$ & $23(28.39)$ & \\
\hline & Psychosis $(+)(18)$ & $1(1.23)$ & $8(9.87)$ & $9(11.11)$ & 0.86 \\
\hline & Psychosis (-) (63) & $8(9.87)$ & $25(30.86)$ & $30(37.0)$ & \\
\hline & Seizures $(+)(11)$ & 0 & $5(6.17)$ & $6(7.40)$ & 0.67 \\
\hline & Seizures (-) (70) & $9(11.11)$ & $28(34.56)$ & $33(40.74)$ & \\
\hline & Nephrotoxicity (+) (12) & $1(1.23)$ & $4(4.93)$ & $7(8.64)$ & 0.82 \\
\hline & Nephrotoxicity (-) (69) & $8(9.87)$ & $29(35.80)$ & $32(39.50)$ & \\
\hline & $\mathrm{ACR}(+)(13)$ & $3(3.70)$ & $5(6.17)$ & $5(6.17)$ & 0.32 \\
\hline & ACR (-) (68) & $6(7.40)$ & $28(34.56)$ & $34(41.97)$ & \\
\hline & Sepsis $(+)(20)$ & $2(2.46)$ & $2(2.46)$ & 16(19.75) & $0.002^{*}$ \\
\hline & Sepsis (-) (61) & $7(8.64)$ & $31(38.27)$ & $23(28.39)$ & \\
\hline & & $\mathrm{CC}(\mathrm{n}=4)$ & $\mathrm{CT}(\mathrm{n}=37)$ & $\mathrm{TT}(\mathrm{n}=40)$ & \\
\hline \multirow[t]{12}{*}{ rs1128503 } & Adverse effects $(+)(28)$ & $1(1.23)$ & $13(16.04)$ & $14(17.28)$ & 1.0 \\
\hline & Adverse effects (-) (53) & 3(3.70) & $24(29.62)$ & $26(32.09)$ & \\
\hline & Psychosis (+) (18) & $1(1.23)$ & $8(9.87)$ & $9(11.11)$ & 1.0 \\
\hline & Psychosis (-) (63) & $3(3.70)$ & $29(35.80)$ & $31(38.27)$ & \\
\hline & Seizures $(+)(11)$ & 1(1.23) & $7(8.64)$ & $3(3.70)$ & 0.21 \\
\hline & Seizures (-) (70) & $3(3.70)$ & $30(37.03)$ & $37(45.67)$ & \\
\hline & Nephrotoxicity (+) (12) & 0 & $5(6.17)$ & $7(8.64)$ & 0.88 \\
\hline & Nephrotoxicity (-) (69) & $4(4.93)$ & $32(39.50)$ & $33(40.74)$ & \\
\hline & ACR (+) (13) & $2(2.46)$ & $8(9.87)$ & $3(3.70)$ & $0.04^{*}$ \\
\hline & ACR (-) (68) & $2(2.46)$ & 29() & $37(45.67)$ & \\
\hline & Sepsis $(+)(20)$ & 0 & $7(8.64)$ & $13(16.04)$ & 0.22 \\
\hline & Sepsis (-) (61) & $4(4.93)$ & $30(37.0)$ & $27(33.33)$ & \\
\hline
\end{tabular}

*(statistically significant). 
results in a longer time required to achieve titration to optimal doses. ${ }^{12}$ Identification of specific polymorphisms mediating high interindividual variability in plasma concentration and clinical response will facilitate dosing titration and reduce the time to reach optimal dosing with less risk of developing serious adverse effects. ${ }^{13}$

The present study measured and compared dose-adjusted tacrolimus concentrations in liver transplant recipients with $\mathrm{ABCB} 1$ gene polymorphism of ABCB1 rs1045642(C3435T), rs2032582(G2677T) and rs1128503(C1236T). To our knowledge, this is the first study reporting association of ABCB1 polymorphism with efficacy and adverse effects of tacrolimus in liver transplant recipients in Pakistani population.

The higher number of male recipients in our study is in agreement with similar studies reporting a higher number of male recipients due to an imperfect model for end-stage-liver-disease (MELD) score. ${ }^{14}$

In our study, the ABCB1 rs1045642 CC genotype showed lower tacrolimus concentration-to-dose ratio (CDR) in post-transplantation period week$1(p=0.02)$. Consistent with our findings, a study reported higher tacrolimus dose requirement in recipients with CC genotype as compared to those with CT and TT genotype on first day, third day and three months follow-up posttransplantation period. ${ }^{7}$

Other research studies on Chinese liver-transplant recipients have found a higher dose-adjusted tacrolimus CDR at different post-transplantation periods in recipients carrying the ABCB1 T-allele as compared to recipients with homozygous $C C$ genotype of ABCB1 C3435T. ${ }^{15}$ Factors responsible for variation in bioavailability of tacrolimus could be the fact that homozygous 3435CC variant of ABCB1 gene exhibits significantly lower expression of intestinal P-gp as compared to individuals with ABCB1 3435TT genotype thus affecting bioavailability of tacrolimus. , $^{56-17}$

According to our findings, transplant recipients with polymorphism in rs2032582 and rs1128503 had consistently higher levels of CDR throughout week-1 to week-4 although these findings were not statistically significant. Our findings are in agreement with previous studies that did not find a significant association of ABCB1 G2677T/A and $\mathrm{C} 1236 \mathrm{~T}$ polymorphism on tacrolimus pharmacokinetic parameters during the first six months in renal and liver transplant recipients. Nonetheless, another study has reported high dose tacrolimus requirements in kidney transplant recipients who were carriers of the ABCB1 2677GG wild-type genotype. ${ }^{18,19}$

High plasma levels of tacrolimus have the potential to precipitate neurotoxicity, nephrotoxicity, sepsis and gastrointestinal adverse effects in the post-transplantation period. ${ }^{20} \mathrm{We}$ found a significant association of polymorphism in rs1045642 with psychosis which is consistent with our earlier findings of a higher incidence of psychosis in liver transplant recipients with higher tacrolimus levels. ${ }^{21}$ These findings are in agreement with previous studies which have shown a higher incidence of tacrolimus-related neurotoxicity in the presence of T allele rs1045642. ${ }^{22}$

Recipients with TT polymorphism in rs2032582 showed a significant association with sepsis which is in agreement with our previous findings showing a higher incidence of sepsis in recipients with higher blood tacrolimus levels. ${ }^{21}$ As tacrolimus is a potent immune suppressant drug therefore higher levels of this drug may increase the risk of contracting infections and sepsis.

Recipients with $\mathrm{C}>\mathrm{T}$ polymorphism in rs1128503 had a higher incidence of ACR which was statistically significant. Studies in agreement with our results have shown that lower trough levels of tacrolimus are significantly associated with increased risk of ACR. ${ }^{23,24}$ This finding is also in agreement with our earlier findings showing a higher incidence of ACR in recipients with low blood levels of tacrolimus. ${ }^{21}$

Limitations of the study: The effects of genetic polymorphism of candidate genes on long term adverse effects of tacrolimus were not observed which is one possible limitation of our study.

\section{CONCLUSION}

The present study concludes that polymorphism in the ABCB1 rs1045642 may result in variation in tacrolimus dose requirement during dose titration and clinical efficacy. Significant association of polymorphism in rs1045642 with neurotoxicity, rs2032582 with sepsis and rs1128503 with ACR in liver transplantation recipients is found in Pakistani liver transplant recipients. Based on our results, we propose that identifying polymorphism of ABCB1 rs1045642 may shorten the time to achieve optimum levels of tacrolimus during dose titration. In future studies, the effect of polymorphism on long term adverse effects of tacrolimus should be explored. 
Grant support $\mathcal{E}$ financial disclosures: Shifa Tameer-e-Millat University funded this research.

Conflict of Interest: None.

\section{REFERENCES}

1. Ascha MS, Ascha ML, Hanouneh IA. Management of immunosuppressant agents following liver transplantation: Less is more. World J Hepatol. 2016;8(3):148-161. doi: 10.4254 /wjh.v8.i3.148

2. Moini M, Schilsky ML, Tichy EM. Review on immunosuppression in liver transplantation. World J Hepatol. 2015;7(10):1355-1368. doi: 10.4254/wjh.v7.i10.1355

3. Mohammadpour N, Elyasi S, Vahdati N, Mohammadpour $\mathrm{AH}$, Shamsara J. A review on therapeutic drug monitoring of immunosuppressant drugs. Iran J Basic Med Sci. 2011;14(6):485-498.

4. Hesselink DA, Bouamar R, Elens L, van Schaik RH, van Gelder $\mathrm{T}$. The role of pharmacogenetics in the disposition of and response to tacrolimus in solid organ transplantation. Clin Pharmacokinet. 2014;53:123-139. doi: 10.1007/s40262013-0120-3

5. Shi Y, Li Y, Tang J, Zhang J, Zou Y, Cai B, et al. Influence of CYP3A4, CYP3A5 and MDR-1 polymorphisms on tacrolimus pharmacokinetics and early renal dysfunction in liver transplant recipients. Gene. 2013;512:226-231. doi: 10.1016/j.gene.2012.10.048

6. Hu R, Barratt DT, Coller JK, Sallustio BC, Somogyi AA. CYP3A5*3 and ABCB1 61A $>$ G Significantly Influence Doseadjusted Trough Blood Tacrolimus Concentrations in the First Three Months Post-Kidney Transplantation. Basic Clin Pharmacol Toxicol. 2018;123(3):320-326. doi: 10.1111/ bcpt.13016

7. Helal M, Obada M, Elrazek WA, Safan M, El-Hakim TA, ElSaid H. Effect of ABCB1 (3435C>T) and CYP3A5 (6986A>G) genes polymorphism on tacrolimus concentrations and dosage requirements in liver transplant patients. Egypt J Med Hum Genet. 2017;18(3):261-268.

8. Kim RB, Leake BF, Choo EF, Dresser GK, Kubba SV, Schwarz UI, et al. Identification of functionally variant MDR1 alleles among European Americans and African Americans. Clin Pharmacol Ther. 2001;70:189-199. doi: $10.1067 / \mathrm{mcp} .2001 .117412$

9. Dar FS, Bhatti ABH, Dogar AW, Zia H, Amin S, Rana A, et al. The travails of setting up a living donor liver transplant program: Experience from Pakistan and lessons learned. Liver Transplant. 2015;21:982-990. doi: 10.1002/lt.24151

10. Dar FS, Zia H, Bhatti ABH, Rana A, Nazer R, Kazmi R, et al. Short-term donor outcomes after hepatectomy in living donor liver transplantation. J Coll Physicians Surg Pak. 2016;26:272-276.

11. van Gelder T, Meziyerh S, Swen JJ, de Vries APJ, Moes DJAR. The Clinical Impact of the C0/D Ratio and the CYP3A5 Genotype on Outcome in Tacrolimus Treated Kidney Transplant Recipients. Front Pharmacol. 2020;11:1142. doi: 10.3389/fphar.2020.01142

12. Provenzani A, Santeusanio A, Mathis E, Notarbartolo M, Labbozzetta M, Poma $\mathrm{P}$, et al. Pharmacogenetic considerations for optimizing tacrolimus dosing in liver and kidney transplant patients. World J Gastroenterol. 2013;19(48):9156-9173. doi: 10.3748/wjg.v19.i48.9156

13. Garcia-Gonzalez X, Cabaleiro T, Herrero M, McLeod H, López-Fernández LA. Clinical implementation of pharmacogenetics. Drug Metabol Pers Ther. 2016;31(1):9-16. doi: 10.1515/dmpt-2015-0031
14. Puoti F, Ricci A, Nanni-Costa A, Ricciardi W, Malorni W, Ortona E. Organ transplantation and gender differences: A paradigmatic example of intertwining between biological and sociocultural determinants. Biol Sex Differ. 2016;7:35. doi: 10.1186/s13293-016-0088-4

15. Wei-lin W, Jing J, Shu-sen Z, Li-hua W, Ting-bo L, Song-feng $\mathrm{Y}$, et al. Tacrolimus dose requirement in relation to donor and recipient $\mathrm{ABCB} 1$ and $\mathrm{CYP} 3 \mathrm{~A} 5$ gene polymorphisms in Chinese liver transplant patients. Liver Transpl. 2006;12:775780. doi: 10.1002/lt.20709

16. Li D, Zhu JY, Gao J, Wang X, Lou YQ, Zhang GL. Polymorphisms of tumor necrosis factor-alpha, interleukin-10, cytochrome P450 3A5 and ABCB1 in Chinese liver transplant patients treated with immunosuppressant tacrolimus. Clin Chim Acta. 2007;383:133-139. doi: 10.1016/i.cca.2007.05.008

17. Fernando ME, Sellappan M, Srinivasa Prasad ND, Suren $\mathrm{S}$, Thirumalvalavan K. Influence of CYP3A5 and ABCB1 polymorphism on tacrolimus drug dosing in South Indian renal allograft recipients. Indian J Nephrol. 2019;29:261-266. doi: 10.4103/ijn.IJN_97_18

18. Provenzani A, Notarbartolo $M$, Labbozzetta $M$, Poma $P$, Vizzini G, Salis P, et al. Influence of CYP3A5 and ABCB1 gene polymorphisms and other factors on tacrolimus dosing in Caucasian liver and kidney transplant patients. Int J Mol Med. 2011;28(6):1093-1102. doi: 10.3892/ijmm.2011.794

19. Prasad N, Jaiswal A, Behera MR, Agarwal V, Kushwaha $\mathrm{R}$, Bhadauria D, et al. Melding Pharmacogenomic Effect of MDR1 and CYP3A5 Gene Polymorphism on Tacrolimus Dosing in Renal Transplant Recipients in Northern India. Kidney Int Rep. 2019;5(1):28-38. doi: 10.1016/j. ekir.2019.09.013

20. Xie M, Rao W, Sun LY, Zhu ZJ, Deng YL, Shen ZY, et al. Tacrolimus-related seizure after pediatric liver transplantation - a single-center experience. Pediatr Transplant. 2014;18:58-63. doi: 10.1111/petr.12198

21. Azam F, Khan M, Bhatti ABH, Dar FS, Ahmad A, Javed N. Clinical Efficacy and Safety of Tacrolimus in Pakistani Living Donor Liver Transplant Recipients. J Coll Physicians Surg Pak. 2019;29(11):1048-1052. doi: 10.29271/jcpsp.2019.11.1048

22. Yamauchi A, Ieiri I, Kataoka Y, Tanabe M, Nishizaki T, Oishi R, et al. Neurotoxicity induced by tacrolimus after liver transplantation: relation to genetic polymorphisms of the ABCB1 (MDR1) gene. Transplantation. 2002;74:571-572. doi: 10.1097/00007890-200208270-00024

23. Staatz C, Taylor P, Tett $S$. Low tacrolimus concentrations and increased risk of early acute rejection in adult renal transplantation. Nephrol Dial Transplant. 2001;16(9):1905-1909. doi: $10.1093 / \mathrm{ndt} / 16.9 .1905$

24. Gaynor JJ, Ciancio G, Guerra G, Sageshima J, Roth D, Goldstein MJ, et al. Lower tacrolimus trough levels are associated with subsequently higher acute rejection risk during the first 12 months after kidney transplantation. Transpl Int. 2016;29(2):216-226. doi:10.1111/tri.12699

\section{Authors' Contribution:}

FA: Conceived and designed study; collected, analyzed and interpreted data; drafted manuscript. MK and TK: Designed study; interpreted data and drafted manuscript, reviewed final draft.

ABH: Designed study; analyzed and interpreted data; reviewed final draft.

All authors are responsible and accountable for the accuracy and integrity of the work. 